\title{
Aplicação de diferentes revestimentos na conservação pós-colheita da banana cv. Prata
}

\author{
Sonara de França SOUSA ${ }^{1 *}$, Regilane Marques FEITOSA ${ }^{1}$, Rossana Maria Feitosa de FIGUEIRÊDO ${ }^{2}$
}

${ }^{1}$ Centro de Ciências e Tecnologia, Programa de Pós-Graduação em Engenharia de Processos, Universidade Federal de Campina Grande, Campina Grande, PB, Brasil.

${ }^{2}$ Centro de Tecnologia e Recursos Naturais, Programa de Pós-Graduação em Engenharia Agrícola, Universidade Federal de Campina Grande, Campina Grande, PB, Brasil.

*E-mail: sonara_franca@yahoo.com.br

Recebido em setembro/2017; Aceito em julho/2018.

\begin{abstract}
RESUMO: Objetivou-se avaliar o efeito de diferentes revestimentos sob a conservação da banana cv. prata armazenada em temperatura ambiente. As bananas foram adquiridas em estágio verde de maturação, sendo posteriormente higienizadas e revestidas com as soluções de revestimentos obtidas a partir da gelatina, pectina e goma xantana, a 1\%. As bananas revestidas e a amostra controle, foram armazenadas por 9 dias, quantificadas a partir do tempo 0 quanto aos atributos: perda de massa, cor, acidez, teor de água, sólidos solúveis e pH. De acordo com os resultados obtidos, os tratamentos com gelatina e pectina apresentaram crescimento fúngico ao final do armazenamento. A perda e massa foi maior nas bananas controle, os valores de $L^{*}, a^{*}$ e $b^{*}$, ao final do armazenamento, indicaram uma coloração escura com tendência ao vermelho-amarelado. A acidez das amostras aumentou e os valores de $\mathrm{pH}$ diminuíram e o teor de sólidos solúveis apresentaram acréscimos durante o período de armazenamento. Dentre as soluções de revestimento utilizadas para este estudo, a goma xantana apresentou os melhores resultados, visto que foi a mais eficiente contra a perda de massa e apresentou as menores variações referentes à coloração das bananas.
\end{abstract}

Palavras-chave: goma xantana, perda de massa, armazenamento.

\section{Application of different coating in banana post-harvest conservation cv. Silver}

\begin{abstract}
The objective of the present work was evaluate the effect of different coatings under banana cv. stored at environment temperature. The bananas were obtained at the green maturation stage, sanitized and coated with the solutions of biopolymers from gelatin, pectin and xanthan gum at $1 \%$. The coated bananas and the control sample were stored for 9 days, quantified from time 0 for the following parameters: loss of mass, color, titratable acidity, water content, soluble solids and $\mathrm{pH}$. According to the results obtained, treatments with gelatin and pectin showed fungal growth at the end of storage. The loss and mass was higher in the control bananas, the values of $\mathrm{L}^{*}, \mathrm{a}^{*}$ and $\mathrm{b}^{*}$, at the end of the storage, indicating a dark color with tendency to reddish-yellow. The acidity of the samples increased and the $\mathrm{pH}$ values decreased, and soluble solids content show presented increases during the storage period. Among the coating solutions used for this study, xanthan gum presented the best results, since it was the most efficient against mass loss and showed the smallest variations regarding the color of bananas.
\end{abstract}

Keywords: xanthan gum, mass loss, storage.

\section{INTRODUÇÃO}

Cultivada em todas as regiões do país, a banana é uma das frutas de maior destaque na agricultura brasileira, com uma produção de 7.271,3 toneladas por ano segundo dados do IBGE (2015). Apesar da sua grande produção e consumo, a banana possui elevado índice de perdas pós-colheita, o que limita a sua comercialização sob a forma "in natura". Segundo Vieira (2016), as perdas qualitativas e quantitativas são significativas em toda cadeia produtiva da banana e correspondem a cerca de $20 \%$ entre a colheita, armazenamento, distribuição e venda.

A banana caracteriza-se como um fruto climatério, logo, continua sua atividade fisiológica após ser colhida. Desta forma, há a necessidade de se buscar novas técnicas de conservação pós-colheita que visem prolongar seu período de armazenamento durante a fase pré-climatérica, no qual os frutos se encontram no estágio verdes (RINALDI et al., 2010). A aplicação de revestimentos em produtos vegetais tem-se mostrado como uma técnica bastante eficiente, tais películas, quando aplicadas sobre a superfície de alimentos, geralmente são capazes de reduzir as taxas de degradação, estendendo a vida útil do produto. Os revestimentos são geralmente formados a partir de soluções de biopolímeros comestíveis, como polissacarídeos e proteínas, ou de lipídios, como ceras (AZEREDO et al., 2012).

As coberturas comestíveis, além de serem atóxicas, têm como objetivo uma ação funcional, que aliada a outros métodos possa contribuir na manutenção da qualidade do produto, retardo da deterioração, manutenção do valor nutricional e controle de doenças pós-colheita, uma vez que regulam as atividades metabólicas do fruto armazenado, conferindo brilho como fator atraente para o consumidor (SILVA et al., 2011b, ASSIS; BRITTO, 2014).

Diante do exposto, objetivou-se avaliar o efeito de diferentes polímeros de revestimentos sob a conservação da banana cv. prata armazenada a temperatura ambiente. 


\section{MATERIAL E MÉTODOS}

O presente trabalho foi realizado no Laboratório de Armazenamento e Processamento de Produtos Agrícolas da Universidade Federal de Campina Grande, Campina Grande, PB.

Os cachos de banana cv. prata foram obtidas no comércio local da cidade de Campina Grande, no período de outubro de 2016, em estágio de maturação verde e livre de danos mecânicos e infestações fúngicas. As bananas foram submetidas a higienização e sanitização em água clorada a 0,1 $\mathrm{g} \mathrm{L}^{-1}$ por 15 minutos, posteriormente estas foram secas a temperatura ambiente e acondicionadas em bandeja de poliestireno.

Foram utilizados três tipos de revestimentos para a obtenção das soluções: gelatina, pectina e goma xantana, dos quais foram devidamente pesados em balança analítica e posteriormente diluídos e homogeneizados em água destilada morna $\left( \pm 50^{\circ} \mathrm{C}\right)$. A concentração utilizada foi de $1 \%(\mathrm{p} / \mathrm{p})$ para todas as soluções. As bananas verdes foram mergulhadas por 2 minutos nestas soluções e deixadas secar para que formasse a película de recobrimento nos frutos.

Depois de secas, as bananas foram armazenadas sob condições ambientais $\left(24,3 \pm 5^{\circ} \mathrm{C}\right.$ e $74 \pm 4 \%$ U.R), sendo avaliadas a cada três dias, em triplicata, por 9 dias, de acordo com as seguintes analises: perda de massa: obtida após pesagem individual das frutas em balança analítica, considerando a diferença do peso inicial e o peso após cada avaliação, em porcentagem; cor: através de espectofotômetro Mini Scan Hunter Lab XE Plus, onde foram determinados os valores de: $\mathrm{L}^{*}$ luminosidade; $\mathrm{a}^{*}$ transição da cor verde $\left(-\mathrm{a}^{*}\right)$ para o vermelho $\left(+a^{*}\right)$; e b* transição da cor azul $\left(-b^{*}\right)$ para a cor amarela $\left(+b^{*}\right)$; acidez titulável (expressos em g de ácido málico por $100^{-1}$ ) e o teor de água (expresso em \%) de acordo com as normas Analíticas do Instituto Adolfo Lutz (BRASIL, 2008); pH, determinado através do método potenciométrico, com um pHmetro previamente calibrado com soluções tampão 7,0 e 4,0; e sólidos solúveis (SS): determinados por leitura em refratômetro portátil de bancada.

$\mathrm{O}$ delineamento experimental utilizado foi inteiramente casualizado em esquema fatorial $4(0,3,6$ e 9 dias de armazenamento $) \times 4$ (tratamentos). A variável perda de massa foi analisada por curva de regressão. Os resultados obtidos das análises físico-químicas foram submetidos à análise de variância pelo teste de Tukey $5 \%$ de probabilidade utilizando o Software de Assistência Estatística ASISTAT versão 7.7.

\section{RESULTADOS}

$\mathrm{Na}$ Figura 1, constata-se o aumento da perda de massa durante todo o período analisado, sendo que a máxima foi de $48,75 \%$ para a amostra controle e a menor perda foi observada com o revestimento a base de goma xantana, sendo encontrada uma média de $36,79 \%$, ao final do armazenamento.

Analisando-se a influência dos revestimentos sobre a luminosidade (Tabela 1), verifica-se um comportamento indefinido para este parâmetro, porém, a goma xantana se destaca entre os demais revestimentos aplicados, apresentando maior luminosidade ao longo do armazenamento. Já com relação ao tempo de armazenamento, observa-se que para todos os tratamentos houve decréscimo da luminosidade, evidenciando o escurecimento das cascas.

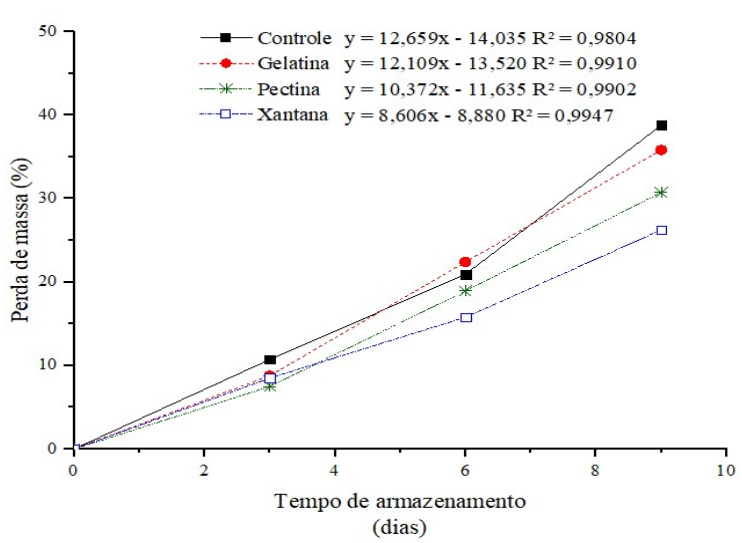

Figura 1. Perda de massa da banana cv. prata sob diferentes revestimentos e armazenada a temperatura ambiente.

Figure 1. Mass loss of banana cv. silver under different coatings and stored at environment temperature.

Tabela 1. Valores médios e desvios-padrão para a luminosidade das bananas prata sob diferentes revestimentos.

Table 1. Mean values and standard deviations for the brightness of silver bananas under different coatings.

\begin{tabular}{ccccc}
\hline \multirow{2}{*}{$\begin{array}{c}\text { Tempo de } \\
\text { armazenamento } \\
\text { (Dias) }\end{array}$} & Controle & Gelatina & Pectina & Xantana \\
\cline { 2 - 5 } & & & & \\
\hline 0 & $54,43 \mathrm{aA}$ & $54,43 \mathrm{aA}$ & $54,43 \mathrm{aA}$ & $54,43 \mathrm{aA}$ \\
3 & $45,46 \mathrm{bD}$ & $53,91 \mathrm{aA}$ & $48,34 \mathrm{bC}$ & $51,66 \mathrm{bB}$ \\
6 & $35,64 \mathrm{cC}$ & $34,76 \mathrm{bD}$ & $37,44 \mathrm{cB}$ & $40,92 \mathrm{cA}$ \\
9 & $18,32 \mathrm{~dB}$ & - & - & $35,52 \mathrm{dA}$ \\
\hline Média & 38,46 & 47,70 & 46,74 & 45,63 \\
D.P & 15,46 & 11,20 & 8,60 & 8,91 \\
\hline
\end{tabular}

D.P: desvio padrão. D.M.S para colunas $=0,8024$. D.M.S para linhas $=$ 0,8024. Médias seguidas por letra minúsculas nas colunas, e médias seguidas por letras maiúsculas nas linhas, não diferem estatisticamente (Tukey, p > $0,05)$

Analisando-se o parâmetro $\pm \mathrm{a}^{*}$ (Tabela 2), podemos observar que ocorreu a transição da fase do amadurecimento para todos os frutos, onde todas as amostras passaram da tonalidade verde (tempo 0) para o avermelhado a partir do $3^{\circ}$ dia de armazenamento; o revestimento com goma xantana apresentou as menores médias até o $6^{\circ}$ dia. Em relação ao tempo de armazenamento, pode-se verificar que a tonalidade vermelha foi mais evidenciada durante o $6^{\circ}$ dia, para todos os tratamentos testados.

Tabela 2. Valores médios e desvios-padrão para a intensidade verde $\left(-a^{*}\right)$ e vermelho $\left(+a^{*}\right)$ das bananas prata sob diferentes revestimentos.

Table 2. Mean values and standard deviations for the intensity green color $\left(-\mathrm{a}^{*}\right)$ and red color $\left(\mathrm{a}^{*}\right)$ of the silver bananas under different coatings.

\begin{tabular}{ccccc}
\hline \multirow{2}{*}{$\begin{array}{c}\text { Tempo de } \\
\text { armazenamento } \\
\text { (Dias) }\end{array}$} & Controle & Gelatina & Pectina & Xantana \\
\cline { 2 - 5 } & & & & \\
\hline 0 & $-7,41 \mathrm{dA}$ & $-7,41 \mathrm{bA}$ & $-7,41 \mathrm{cA}$ & $-7,41 \mathrm{dA}$ \\
3 & $6,75 \mathrm{bB}$ & $6,49 \mathrm{cB}$ & $7,88 \mathrm{bA}$ & $4,68 \mathrm{cC}$ \\
6 & $10,97 \mathrm{aA}$ & $9,70 \mathrm{aB}$ & $9,70 \mathrm{aB}$ & $9,20 \mathrm{aC}$ \\
9 & $3,17 \mathrm{cB}$ & - & - & $6,07 \mathrm{bA}$ \\
\hline Média & 3,37 & 2,92 & 3,39 & 3,13 \\
D.P & 7,86 & 9,09 & 9,40 & 7,28 \\
\hline
\end{tabular}

D.P: desvio padrão. D.M.S para colunas $=0,3312$. D.M.S para linhas $=$ 0,3312. Médias seguidas por letra minúsculas nas colunas, e médias seguidas por letras maiúsculas nas linhas, não diferem estatisticamente (Tukey, p > $0,05)$ 
Analisando-se o parâmetro b* (Tabela b), constata-se que a aplicação dos revestimentos testados não apresentou diferenças significativas entre si, apresentando ao longo do armazenamento uma coloração amarelada. Com relação ao tempo de armazenamento, observa-se uma tendência de decréscimo da tonalidade amarela, sendo que os frutos revestidos com goma xantana apresentaram maior estabilidade em relação à pigmentação, mostrando uma maior proteção em relação à perda da cor.

Sobre a acidez titulável (Tabela 4), observa-se que os filmes utilizados não influenciaram no parâmetro estudado. Com relação ao tempo de armazenamento, pode-se verificar que a acidez titulável aumentou apenas do tempo 0 ao $3^{\circ}$ dia, mantendo-se estável, em todos os tratamentos, até o $9^{\circ}$ dia.

Com relação aos valores dos teores de água das amostras (Tabela 5), observa-se que estes diminuíram significativamente ao longo do período de armazenamento e que os revestimentos não foram eficientes para evitar o murchamento das bananas, como pode ser comprovado, também, pelos resultados anteriormente citados na Figura 1.

Sobre os valores de $\mathrm{pH}$ das amostras (Tabela 6), analisando-se o efeito do tempo de armazenamento, observase decréscimos, tal resultado corrobora com a acidez, já que estes parâmetros físico-químicos apresentam comportamentos inversos. Porém, com relação ao efeito dos revestimentos, ainda é possível verificar que a goma xantana se sobressai, quando comparada a controle, mantendo o $\mathrm{pH}$ estável do tempo 6 ao 9 .

Tabela 3. Valores médios e desvios-padrão para a intensidade de amarelo $\left(+b^{*}\right)$ das bananas prata sob diferentes revestimentos.

Table 3. Mean values and standard deviations for the intensity of the yellow color $(b *)$ of the silver bananas under different coatings.

\begin{tabular}{ccccc}
\hline \multirow{2}{*}{$\begin{array}{c}\text { Tempo de } \\
\text { armazenamento } \\
\text { (Dias) }\end{array}$} & \multicolumn{4}{c}{ Parâmetro +b* } \\
\cline { 2 - 5 } & Controle & Gelatina & Pectina & Xantana \\
3 & $42,89 \mathrm{aA}$ & $42,89 \mathrm{aA}$ & $42,89 \mathrm{aA}$ & $42,89 \mathrm{aA}$ \\
6 & $35,49 \mathrm{abA}$ & $44,27 \mathrm{aA}$ & $43,56 \mathrm{aA}$ & $44,71 \mathrm{aA}$ \\
9 & $28,99 \mathrm{bcA}$ & $27,65 \mathrm{bA}$ & $30,95 \mathrm{aA}$ & $35,87 \mathrm{abA}$ \\
\hline Média & $16,59 \mathrm{cA}$ & - & - & $24,56 \mathrm{bA}$ \\
D.P & 30,99 & 38,27 & 39,13 & 37,01 \\
\hline
\end{tabular}

D.P: desvio padrão. D.M.S para colunas $=12,7694$. D.M.S para linhas $=12,7694$. Médias seguidas por letra minúsculas nas colunas, e médias seguidas por letras maiúsculas nas linhas, não diferem estatisticamente (Tukey, $\mathrm{p}>0,05$ )

Tabela 4. Valores médios e desvios-padrão para a acidez titulável das bananas prata sob diferentes revestimentos.

Table 4. Mean values and standard deviations for titratable acidity of silver bananas under different coatings.

\begin{tabular}{ccccc}
\hline \multirow{2}{*}{$\begin{array}{c}\text { Tempo de } \\
\text { armazenamento } \\
\text { (Dias) }\end{array}$} & Controle & Gelatina & Pectina & Xantana \\
\cline { 2 - 5 } & & & & \\
\hline 0 & $0,14 \mathrm{bB}$ & $0,23 \mathrm{bA}$ & $0,16 \mathrm{bAB}$ & $0,15 \mathrm{bB}$ \\
3 & $0,36 \mathrm{aA}$ & $0,34 \mathrm{aAB}$ & $0,28 \mathrm{aB}$ & $0,33 \mathrm{aAB}$ \\
6 & $0,36 \mathrm{aA}$ & $0,37 \mathrm{aA}$ & $0,36 \mathrm{aA}$ & $0,36 \mathrm{aA}$ \\
9 & $0,38 \mathrm{aA}$ & - & - & $0,37 \mathrm{aA}$ \\
\hline Média & 0,24 & 0,31 & 0,27 & 0,24 \\
D.P & 0,13 & 0,07 & 0,10 & 0,12 \\
\hline
\end{tabular}

D.P: desvio padrão. D.M.S para colunas $=0,0659$. D.M.S para linhas $=$ 0,0659 . Médias seguidas por letra minúsculas nas colunas, e médias seguidas por letras maiúsculas nas linhas, não diferem estatisticamente (Tukey, p > $0,05)$
Tabela 5. Valores médios e desvios-padrão para o teor de água das bananas prata sob diferentes revestimentos.

Table 5. Mean values and standard deviations for water content of silver bananas under different coatings.

\begin{tabular}{ccccc}
\hline \multirow{2}{*}{$\begin{array}{c}\text { Tempo de } \\
\text { armazenamento } \\
\text { (Dias) }\end{array}$} & Controle & Gelatina & Pectina & Xantana \\
\cline { 2 - 5 } & & & & \\
\hline 0 & $75,89 \mathrm{aA}$ & $75,81 \mathrm{aA}$ & $75,50 \mathrm{aA}$ & $76,01 \mathrm{aA}$ \\
3 & $75,19 \mathrm{aA}$ & $70,41 \mathrm{bB}$ & $70,84 \mathrm{bAB}$ & $75,94 \mathrm{aA}$ \\
6 & $72,21 \mathrm{bA}$ & $66,68 \mathrm{cB}$ & $66,69 \mathrm{cB}$ & $71,34 \mathrm{bA}$ \\
9 & $66,69 \mathrm{cA}$ & - & - & $66,69 \mathrm{cA}$ \\
\hline Média & 72,49 & 70,97 & 71,01 & 72,74 \\
D.P & 4,18 & 4,58 & 4,41 & 4,72 \\
\hline
\end{tabular}

D.P: desvio padrão. D.M.S para colunas $=1,5548$. D.M.S para linhas $=$ 1,5548. Médias seguidas por letra minúsculas nas colunas, e médias seguidas por letras maiúsculas nas linhas, não diferem estatisticamente (Tukey, $\mathrm{p}>$ $0,05)$

Tabela 6. Valores médios e desvios-padrão para o $\mathrm{pH}$ das bananas prata sob diferentes revestimentos

Table 6. Mean values and standard deviations for the $\mathrm{pH}$ of silver bananas under different coatings

\begin{tabular}{ccccc}
\hline \multirow{2}{*}{$\begin{array}{c}\text { Tempo de } \\
\text { armazenamento } \\
\text { (Dias) }\end{array}$} & Controle & Gelatina & Pectina & Xantana \\
\hline 0 & $5,47 \mathrm{aB}$ & $5,13 \mathrm{aC}$ & $5,29 \mathrm{aB}$ & $5,56 \mathrm{aA}$ \\
3 & $5,39 \mathrm{bA}$ & $4,77 \mathrm{bA}$ & $4,77 \mathrm{bA}$ & $5,23 \mathrm{bB}$ \\
6 & $4,77 \mathrm{cA}$ & $4,75 \mathrm{bAB}$ & $4,71 \mathrm{bB}$ & $4,77 \mathrm{cA}$ \\
9 & $4,62 \mathrm{~dB}$ & - & - & $4,78 \mathrm{cA}$ \\
\hline Média & 5,06 & 4,88 & 4,92 & 5,08 \\
D.P & 0,42 & 0,21 & 0,31 & 0,37 \\
\hline
\end{tabular}

D.P: desvio padrão. D.M.S para colunas $=0,0712$. D.M.S para linhas $=$ 0,0712 . Médias seguidas por letra minúsculas nas colunas, e médias seguidas por letras maiúsculas nas linhas, não diferem estatisticamente (Tukey, $p$ > $0,05)$

Com relação aos teores de sólidos totais das frutas revestidas e controle (Tabela 7), verifica-se que o efeito do tempo afetou apenas as bananas revestidas com pectina e goma xantana, reduzindo apenas do tempo 0 ao 3 dia, mantendo-se estável até o fim do armazenamento. Analisando-se o efeito dos revestimentos, verifica-se estabilidade ao longo do armazenamento.

Tabela 7. Valores médios e desvios-padrão para os sólidos solúveis das bananas prata sob diferentes revestimentos

Table 7. Mean values and standard deviations for the soluble solids of the silver bananas under different coatings

\begin{tabular}{ccccc}
\hline \multirow{2}{*}{$\begin{array}{c}\text { Tempo de } \\
\text { armazenamento } \\
\text { (Dias) }\end{array}$} & Controle & Gelatina & Pectina & Xantana \\
\cline { 2 - 5 } & $24,96 \mathrm{aC}$ & $25,23 \mathrm{aC}$ & $33,23 \mathrm{aA}$ & $30,00 \mathrm{aB}$ \\
3 & $24,96 \mathrm{aA}$ & $24,96 \mathrm{aA}$ & $25,23 \mathrm{bA}$ & $24,96 \mathrm{bA}$ \\
6 & $24,96 \mathrm{aA}$ & $24,96 \mathrm{aA}$ & $25,03 \mathrm{bA}$ & $25,26 \mathrm{bA}$ \\
9 & $24,83 \mathrm{aA}$ & - & - & $24,96 \mathrm{bA}$ \\
\hline Média & 24,93 & 25,05 & 27,83 & 26,30 \\
D.P & 0,06 & 0,15 & 4,67 & 2,47 \\
\hline
\end{tabular}

D.P: desvio padrão. D.M.S para colunas $=3,1350$. D.M.S para linhas $=3,1350$. Médias seguidas por letra minúsculas nas colunas, e médias seguidas por letras maiúsculas nas linhas, não diferem estatisticamente (Tukey, $p>0,05$ )

\section{DISCUSSÃO}

As bananas revestidas com as soluções a $1 \%$ de gelatina e pectina apresentaram crescimento fúngico ao final do armazenamento. A perda de massa deve-se à espessura do filme formado, no qual, a goma xantana se apresentou mais viscosa que os demais polímeros utilizados a uma mesma 
concentração. A goma xantana já foi utilizada como revestimento comestível em mamão (CORTEZ-VEJA et al., 2013), maçã (FREITAS et al., 2013), pêssego (PIZATO et al., 2013) e morangos (BORGES et al., 2013) minimamente processados; entretanto, os resultados são dependentes da fruta e das variáveis tempo e temperatura de armazenamento.

A perda de massa quantificada neste trabalho foi maior do que as evidenciadas na literatura, a saber, Simões (2014) ao caracterizar bananas sem revestimento, em dois estágios de maturação aparente (verde e maduro) e destinadas ao mercado externo durante 15 dias de armazenamento a temperatura de $29^{\circ} \mathrm{C}$, verificou que a perda máxima foi de $16,9 \%$, com os frutos apresentando casca com aspecto enrugado. Silva et al. (2011a) ao estudarem a banana cv. Prata revestida com amido de mandioca gelatinizado, nas concentrações de 2, 4, 6, 8 e $10 \%$, armazenadas entre 8 a $10^{\circ} \mathrm{C}$, por 7 dias, observaram que os frutos sem revestimento perderam em média $1,25 \%$ de peso por dia, enquanto que os frutos revestidas perderam peso continuamente ao longo do armazenamento, mostrando que os revestimentos testados não representaram uma barreira significativa contra a perda de umidade.

Trabalhos relacionados à perda de massa em bananas também podem ser verificados em Maia et al. (2011) para a variedade 'Prata Ana' armazenadas a $25,4^{\circ} \mathrm{C}$ e $82 \%$ UR submetidas à danos mecânicos, onde as amostras perderam $11,2 \%$ e $11,8 \%$ (corte e abrasão) e $9,7 \%, 8,1 \%$ e $8,4 \%$ para os frutos danificados por impacto, compressão e controle, respectivamente; e por Aguila et al. (2007) para a variedade 'Nanicão' armazenada por 20 dias a $20^{\circ} \mathrm{C}$ e $60 \%$ UR, em que a maior perda foi de $25,42 \%$ para os frutos cortados.

A perda de massa deve-se principalmente à remoção da água do produto devido a uma maior taxa de transpiração dos frutos, segundo Chitarra; Chitarra, (2005), alguma perda de água pode ser tolerada, mas aquelas responsáveis pelo murchamento ou enrugamento devem ser evitadas.

A cor, assim como outros atributos, constitui um padrão de qualidade à comercialização e utilização dos produtos para a industrialização (SILVA et al., 2013). O parâmetro L*, analisado na Tabela 1, é uma medição da luminosidade, avaliando de maneira a estabelecer uma escala cinza, com valores entre preto (0) e branco (100) (PATHARE et al., 2013). A diminuição da luminosidade nas cascas das bananas deve-se ao padrão respiratório climatérico, caracterizado pela produção de etileno, mesmo após a colheita. O etileno é responsável pelo amadurecimento do fruto e é o principal responsável pelas alterações de pigmentação e características sensoriais (ORMENESE, 2010).

Cardoso et al. (2008), ao avaliarem a qualidade póscolheita de bananas 'Pacovan' utilizando atmosferas modificadas obtidas por filmes plásticos de PVC e de polietileno e biofilme a base de cera de carnaúba a $50 \%$, constataram que os frutos do tratamento com Polietileno não retardaram o processo de maturação estando os mesmos amadurecidos ao final do armazenamento. Montibeller et al. (2016) ao avaliarem o efeito de filmes formados por pectina, albúmen de ovo, carragena, gelatina, fécula de batata, xantana e amido de milho na conservação de banana cv. Caturra, armazenada a $18^{\circ} \mathrm{C} \pm 1^{\circ} \mathrm{C}$ com UR de $80 \% \pm 5 \%$ por 8 dias, observaram a redução de luminosidade, em ordem decrescente, nos tratamentos controle $(19,6 \%)$, xantana $(7 \%)$, carragena $(3,7 \%)$ e pectina $(3,3 \%)$.

$\mathrm{O}$ parâmetro $\mathrm{a}^{*}$ define o eixo que varia entre o verde (-60) e o vermelho $(+60)$, ao passo que, o parâmetro b* representa a variação entre o azul (-60) e o amarelo (+60). As Tabelas 2 e 3 indicam que os revestimentos aplicados não exerceram influencias sobre o amadurecimento dos frutos. Os resultados obtidos corroboram com Montibeller et al. (2016) ao encontrarem valores positivos indicando uma coloração amarelada em todos os tratamentos, durante todo período de armazenamento das bananas cv. Caturra.

Sobre o aumento da acidez titulável (Tabela 4), durante o processo respiratório das bananas, são produzidos ácidos orgânicos que podem acumular-se no fruto, ocasionando um leve aumento da acidez neles (PALIYATH et al., 2008). Resultado semelhante foi observado por Cardoso et al. (2008) onde a acidez das amostras de banana 'Pacovan' obtiveram uma tendência de aumento durante a maturação. Pimentel et al. (2010) encontraram para bananas verdes, da variedade Prata-Anã valores de acidez titulável de $0,18 \%$ e para os frutos maduros acidez de $0,69 \%$.

A redução do teor de água, apresentado na Tabela 5, já era esperada, uma vez que ocorreram perdas de peso das frutas armazenadas, contudo a xantana controlou melhor a migração de água das bananas, apresentando perda sutil para o ambiente ao longo do armazenamento. Bezerra; Dias (2009), avaliando os frutos da bananeira, encontraram valores médios para o teor de água de 74,61\%, estando próximos ao obtidos neste presente estudo.

As médias obtidas para o $\mathrm{pH}$, apresentados na Tabela 6, concordam com as de Lima et al. (2005), cujo valor de $\mathrm{pH}$ encontrado para bananas em estágio de maturação verde foi de 5,20. Simões (2014) observou uma pequena variação nos valores de $\mathrm{pH}$, com valor médio inicial de 5,21 (fruto verde) e valor médio final de 5,16 (fruto maduro), condizente com os resultados obtidos.

Segundo Chitarra; Chitarra (2005), espera-se que durante o amadurecimento ocorra aumento de SS em decorrência da transformação dos polissacarídeos insolúveis em açúcares solúveis, tal característica não foi evidenciada neste estudo. De acordo com os resultados obtidos na literatura, Cardoso et al. (2008) observaram que os teores de sólidos solúveis aumentaram com o tempo de armazenamento. Montibeller et al. (2016) observaram que os teores de sólidos solúveis (SS) apresentaram valores entre 16,9 a $25,1{ }^{\circ}$ Brix, durante o armazenamento de banana cv. Caturra. Comportamento semelhante a este estudo foi observado por Scalon et al. (2011) que verificaram, que os teores de SS das guaviras (CampomanesiaadamantiumCamb.) diminuíram em todos os revestimentos aplicados ao longo do período de armazenamento. Para os mesmos autores a diminuição desses teores pode significar que os teores iniciais estão servindo de substrato para a senescência e que esta mesma redução pode estar relacionada com o estádio avançado de maturação dos frutos no início do armazenamento.

\section{CONCLUSÕES}

Os revestimentos aplicados não foram eficientes contra a perda de massa dos frutos, bem como, não formaram uma barreira eficiente contra a passagem de água para o meio ambiente. Com relação à cor, as amostras apresentaram diminuição da luminosidade, indicando o escurecimento da casca, com tendência para as tonalidades vermelho-amarelada. De uma forma geral, a acidez titulável das amostras aumentaram ao passo que o $\mathrm{pH}$ diminuiu em relação ao tempo de armazenamento. Os sólidos solúveis apresentaram decréscimos. As características das coberturas dependem não 
só das suas propriedades de barreira, como também das propriedades fisiológicas dos frutos e dos fatores ambientais no qual estes são acondicionados. Podemos classificar neste estudo que a goma xantana foi o melhor revestimento testado visto que a perda de massa e as variações referente à coloração das bananas foram menores em relação aos outros tratamentos, entretanto é de fundamental importância o desenvolvimento de pesquisas relacionadas a contribuir para que esta prática seja coerente e acessível em larga escala na conservação póscolheita dos produtos alimentícios.

\section{REFERÊNCIAS}

AGUILA, J. S. HEIFFIG, L. S.; ONGARELLI, M. D.; KLUGE, R. A. Physical and anatomical characterization of mechanical injuries to banana fruit. Revista Iberoamericana de Tecnología Postcosecha, Hermosillo, v. 8, n. 2, p. 60-65, 2007.

ASSIS, O. B. G; BRITTO, D. Revisão: coberturas comestíveis protetoras em frutas: fundamentos e aplicações. Brazilian Journal of Food Technology, v. 17, n. 2, p. 87- 97, 2014. DOI: http://dx.doi.org/10.1590/bjft.2014.019

AZEREDO, H. M. C.; MIRANDA, W. E.; RIBEIRO, H. L. Revestimentos Comestíveis de Alginato e Polpa de Acerola. Fortaleza: Embrapa Agroindustria Tropical, 2012. 3 p. (Comunicado técnico, 191)

BEZERRA, V. S.; DIAS, J. S. A. Avaliação físico-química de frutos de bananeiras Revista Acta Amazonica, Manaus, vol. 39, n. 2, p. 423-428, 2009. DOI: http://dx.doi.org/10.1590/S0044-59672009000200022

BORGES, C. D.; MENDONÇA, C. R. B.; ZAMBIAZI, R. C.; NOGUEIRA, D.; SILVA, E. M. P.; PAIVA, F. F. Conservação de morangos com revestimentos à base de goma xantana e óleo essencial de sálvia. Bioscience Journal, Uberlândia, v. 29, n. 5, p. 1071-1083, 2013.

CARDOSO, J. M. S.; SANTOS, A. E. O.; LIMA, M. A. C.; MARQUES, M. A. D.; SILVA, M. G. Utilização de atmosfera modificada na conservação pós-colheita de bananas 'pacovan'. In: Congresso de Pesquisa e Inovação da Rede Norte Nordeste de Educação Tecnológica, 3., 2008, Fortaleza. Anais... Fortaleza: MEC - REDENET. 2008.

CHITARrA, M. I. F.; CHITARRA, A. B. Pós-colheita de frutos e hortaliças: fisiologia e manuseio. 2. ed. Lavras: ESAL/FAEFE, 2005. 785p

CORTEZ-VEJA, W. R.; PIOTROWICZ, I. B. B.; PRENTICE, C.; BORGES C. D. Conservação de mamão minimamente processado com uso de revestimento comestível à base de goma xantana. Semina: Ciências Agrárias, Londrina, v. 34, n. 4, p. 1753-1764, 2013. DOI: http://dx.doi.org/10.5433/1679-0359.2013v34n4p1753

FREITAS, I. R.; CORTEZ-VEJA, W. R.; PIZATO, S.; PRENTICE-HERNÁNDEZ, C.; BORGES, C. D. Xanthan gum as a carrier of preservative agents and calcium chloride applied on fresh-cut apple. Journal Food Safety, New Brunswick, v. 33, n. 3, p. 229-238, 2013. DOI: https://dx.doi.org/10.1111/jfs.12044

IBGE INSTITUTO BRASILEIRO DE GEOGRAFIA E ESTATÍSTICA. Dados da produção e consumo de banana no Brasil, 2015. Disponível em: <www.ibge.gov.br>. Acesso em: 25/09/2016.
INSTITUTO ADOLFO LUTZ (IAL). Métodos físicoquímicos para análise de alimentos. 4. Ed. São Paulo: IAL, 2008. 1020p.

LIMA, L. C.; COSTA, S. M.; DIAS, M. S. C.; MARTINS, R. N.; RIBEIRO, J. R. P. M. Controle do amadurecimento de banana 'prata-anã', armazenada sob refrigeração e atmosfera modificada passiva com o uso do 1metilciclopropeno. Ciência e Agrotecnologia, Lavras, v. 29, n. 2, p. 476-80, 2005. DOI: http://dx.doi.org/10.1590/S1413-70542005000200028

MAIA, V. M.; SALOMÃO, L. C. C.; SIQUEIRA, D. L.; PUSCHMAN, R.; MOTA FILHO, V. J. G.; CECON, P. R. Physical and metabolic alterations in "Prata-Anã" bananainduced by mechanical damage at room temperature. Scientia Agricola. Piracicaba, v. 68, n. 1, p. 31-36, 2011. DOI: http://dx.doi.org/10.1590/S010390162011000100005

MONTIBELLER, M. J.; ZAPAROLLI, F. B.; OLIVEIRA, B. G.; PIETROWSKI, G. A. M.; ALMEIDA, D. M. Efeito de filmes de polímeros naturais na conservação de banana cv. caturra (Musa paradisiaca L.). Revista Brasileira de Produtos Agroindustriais, Campina Grande, v. 18, n. 1, p. 11-19, 2016.

ORMENESE, S. C. R. Obtenção de farinha de banana verde por diferentes processos de secagem e aplicação em produtos alimentícios. 2010. 182f. Doutorado (Tecnologia em Alimentos) - Faculdade de Engenharia de Alimentos, Campinas, 2010.

PALIYATH, P.; MURR, D. P.; HANDA, K. A.; LURIE,S. Postharvest biology and technology of fruits, vegetable, and flowers. Ames: Wiley-Blackwell, 2008. 482 p.

PATHARE, P. B.; OPARA, U. L.; AL-SAID, F. A-J. Colour measurement and analysis in fresh and processed foods. a review. Food and Bioprocess Technology, New York, v. 6 , n. $1, \quad$ p. $36-60, \quad 2013$. DOI: https://doi.org/10.1007/s11947-012-0867-9

PIMENTEL, R. M. de M.; GUIMARÃES, F. N.; SANTOS, V. M.; RESENDE, J. C. F. Qualidade pós-colheita dos genótipos de banana PA42-44 e Prata-Anã cultivados no norte de Minas Gerais. Revista Brasileira de Fruticultura, Jaboticabal, v. 32, n. 2, jun. 2010. DOI: http://dx.doi.org/10.1590/S0100-29452010005000047

PIZATO, S.; CORTEZ-VEGA, W. R.; DE SOUZA, J. T. A.; PRENTICE-HERNÁNDEZ, C.; BORGES, C. D. Effects of different edible coatings in physical, chemical and microbiological characteristics of minimally processed peaches (Prunuspersica (L.) Batsch). Journal of Food Safety, New Brunswick, v. 33, n. 1, p. 30-39, 2013. DOI: https://doi.dx.org/10.1111/jfs.12020

RINALDI, M. M.; CARMO, N. R.; SALES, R. N. Conservação pós-colheita de banana Nanicão e Prata. Planaltina - DF: Embrapa Cerrados, 2010. 29 p.

SCALON, S. P. Q.; OSHIRO, A. M.; DRESCH, D. M. Conservação pós-colheita de guavira (Campomanesia adamantium Camb.) sob diferentes revestimentos e temperaturas de armazenamento. Revista Brasileira de Fruticultura, Jaboticabal, v. 34, n. 4, p. 1022-1029, 2012. DOI: $\quad$ http://dx.doi.org/10.1590/S010029452012000400008.

SILVA, A. A. L. DA; BONOMO, R. C. F.; CHAVES, M. A.; REBOUÇAS, K. H.; SANTOS, T. D. R.; OLIVEIRA, A. A. C. L. Efeitos de revestimentos de amido gelatinizado no 
armazenamento refrigerado de banana Prata (Musa AAB). Revista Brasileira de Produtos Agroindustriais, Campina Grande, v. 13, n. 3, p. 235-241, 2011.

SILVA, D. F. P.; SIQUEIRA, D. L.; SANTOS, D.; MACHADO, D. L. M.; SALOMÃO, L. C. C. Recobrimentos comestíveis na conservação pós-colheita de 'Mexerica-do-Rio'. Revista Brasileira de Fruticultura, Jaboticabal, v. 33, n. spe1, p. 357-362, 2011. DOI: http://dx.doi.org/10.1590/S010029452011000500045

SILVA, S. O.; AMORIM, E. P.; SEREJO, J. A. S.; FERREIRA, C. F.; RODRIGUEZ, M. A. D. Melhoramento genético da bananeira: estratégias e tecnologias disponíveis. Revista Brasileira de Fruticultura, v. 35, n. 3, p. 919-931, 2013. DOI: http://dx.doi.org/10.1590/S0100-29452013000300032

SIMÕES, J. P. O. Caracterização físico-química de bananas destinadas ao mercado externo. Revista Verde de Agroecologia e Desenvolvimento Sustentável, Pombal, v. 9, n. 4, p. 220 - 223, 2014.

VIEIRA, L. M. Banana. Síntese anual da agricultura de Santa Catarina - 2010-2011. Disponível em: < http://docweb.epagri.sc.gov.br/website_cepa/Informativos /Banana/Banana_sintese_2011.pdf $>$ Acesso em: 06 nov 2016. 